\title{
ÁFRICA Y LA COOPERACIÓN PARA EL DESARROLLO: UNA REFLEXIÓN DESDE LA ÉTICA GLOBAL ${ }^{1}$
}

\begin{abstract}
Eduardo A. Carreño
Resumen: Tras la Segunda Guerra Mundial se planteó que, para reducir la pobreza, se necesitaba modernización económica, es decir, las sociedades menos desarrolladas debían seguir el camino de los países industrializados, para lo cual solo se requería de una ayuda que permitiese la evolución y prosperidad en todo el mundo. Sin embargo, este paradigma será cuestionado luego del fin de la Guerra Fría, particularmente al momento de evaluar el impacto en África de la cooperación para el desarrollo. El objetivo de este artículo es, primero, analizar cómo el sistema internacional ha determinado las estrategias políticas y económicas de los países africanos; segundo, abordar el debate ético suscitado en torno a la cooperación para el desarrollo, y tercero estimar el impacto de ésta en las estrategias africanas de superación de la pobreza.
\end{abstract}

Palabras clave: cooperación para el desarrollo, ética global, África, desarrollo, pobreza

\section{Africa and foreign aid for development: a reflection from the perspective of global ethics}

Abstract: After World War II it was suggested that in order to reduce poverty it was needed economic modernization, that is, less developed countries should follow the path of the industrialized countries, for which only it was required aid to allow evolution and prosperity around the world. However, this paradigm was questioned after the end of Cold War, particularly when evaluating the impact on Africa of foreign aid for development. In this sense, the aims of this paper are to analyze how the international system has determined the political and economic strategies of African countries; to address the ethical debate raised on foreign aid for development; and to estimate the impact in African strategies to overcome poverty.

Key words: foreign aid, global ethics, Africa, development, poverty

\section{África e a cooperação para o desenvolvimento: uma reflexão a partir da ética global}

Resumo: Após a Segunda Guerra Mundial se propôs que, para reduzir a pobreza era necessária a modernização econômica, ou seja, as sociedades menos desenvolvidas deveriam seguir o caminho dos países industrializados, para o qual somente era requerida uma ajuda que permitisse a evoluçáo e a prosperidade em todo o mundo. Entretanto, este paradigma será questionado logo após o fim da Guerra Fria, particularmente no momento de avaliar o impacto da cooperação para o desenvolvimento na África. O objetivo deste artigo é, primeiro, analisar como o sistema internacional determinou as estratégias políticas e econômicas dos países africanos; segundo, abordar o debate ético suscitado em torno da cooperaçáo para o desenvolvimento e, terceiro, estimar o impacto desta cooperação nas estratégias africanas de superação da pobreza.

Palavras-chave: cooperação para o desenvolvimento, ética global, África, desenvolvimento, pobreza

\footnotetext{
${ }^{1}$ Una versión preliminar de este trabajo fue presentada en el seminario "Problemas Actuales de la Ética Global", Centro Interdisciplinario de Estudios en Bioética (CIEB) e Instituto de Estudios Internacionales de la Universidad de Chile. Santiago, 16-17 de mayo de 2013.

${ }^{2}$ Instituto de Estudios Internacionales, Universidad de Chile, Chile

Correspondencia: ecarreno@uchile.cl
} 


\section{África en el sistema internacional: considera- ciones generales}

El proceso de descolonización de África colmó de esperanzas a una población local marcada por la desdicha de la esclavitud, por la opresión política, social y cultural, y por el despojo de sus recursos naturales a manos del colonizador europeo. Sin embargo, los años venideros no serían mucho más alentadores, por cuanto los problemas derivados de la imposibilidad de consolidar el Estado postcolonial, la consecuente instrumentalización de éste a favor de un sector en particular de la población y las dificultades domésticas y sistémicas para romper con el esquema de dependencia de las ex metrópolis, han llevado a una persistencia de los conflictos internos y a un empeoramiento en las condiciones de vida en el continente africano.

En este contexto, surge la diplomacia humanitaria coercitiva, aquella que emerge luego de la Guerra Fría y que implica la aparición de un nuevo régimen de soberanía promovido por Occidente: aquellos Estados que no cumplan ciertos requisitos (por ejemplo, régimen político democrático, capacidad de gobierno efectiva, respeto a los derechos humanos) no serán considerados plenamente soberanos y pueden ser intervenidos para "civilizarlos"(1). Al respecto, Itziar Ruiz-Giménez plantea que este nuevo parámetro del orden internacional responde a aquellas narrativas dominantes en los últimos veinte años, que, primero, han intentado explicar el origen de las "nuevas guerras" 3 sobre la base de un discurso racista y de determinismo biocultural, que evoca la época del darwinismo social colonial; segundo, que no visualiza las causas inmediatas que provocan el desencadenamiento de la violencia en unos países pero no en otros y, tercero, que sobredimensiona la variable económica de las guerras africanas, obviándose si existe en ellas la dimensión de cambio $\operatorname{social}(3)$.

\footnotetext{
${ }^{3}$ Son guerras de redes que funcionan a través y alrededor de los Estados. En lugar de ejércitos convencionales, suelen enfrentar y crear alianzas en torno a los recursos manejados por las redes transfronterizas formadas por los titulares de los Estados, los grupos sociales, las diásporas, hombres poderosos, etc. Más que una regresión, las nuevas guerras están ligadas de forma natural con un proceso de transformación social: el nacimiento de nuevas formas de autoridad y formas de regulación alternativa(2).
}

Por otra parte, la inagotable discusión dada en instancias intergubernamentales, comunidades epistémicas y organizaciones no gubernamentales en torno al concepto de "desarrollo" y su alcance en el análisis del quehacer público, ha llevado nuevamente a la comunidad internacional a poner sus ojos en África. Como sostiene Alicia Campos, el debate suscitado luego de la descolonización sobre cómo materializar las transformaciones sociales en los países africanos ha considerado tres dimensiones(4):

El significado mismo del "desarrollo": En un principio se entendió como la reproducción en otros lugares del proceso de industrialización de las economías occidentales, a través de un crecimiento económico basado en la agricultura. En este sentido, a juicio de Gilbert Rist, el binomio "desarrollo/subdesarrollo" introduce la idea de continuidad "sustancial" entre sí, es decir, el estado de "subdesarrollo" no es el inverso del "desarrollo", sino su forma inacabada, siendo - en definitiva- el crecimiento el único método para colmar la diferencia(5).

Posteriormente emergen nuevos conceptos, como alivio de la pobreza, satisfacción de necesidades básicas y desarrollo humano, los cuales se sustentan en el impacto de los cambios sociales en las personas y no solo en parámetros macroeconómicos.

Los agentes: Se privilegió en un comienzo la actuación del Estado postcolonial africano; sin embargo, con el paso del tiempo, los defensores de las bondades del mercado cuestionarán su papel como promotor del desarrollo. Así, en los años venideros se consolida el neoliberalismo como paradigma económico y sus requisitos para el desarrollo económico se asociarán a la liberalización comercial, la privatización, la desregulación y los planes de ajuste estructural.

Las causas del "subdesarrollo": Se ha discutido sobre el impacto de las distintas políticas para superar esta condición, poniendo énfasis en las carencias estructurales de los países pobres. Así, por ejemplo, para Paul Collier el desarrollo de África se encuentra atrapado por tres trampas interrelacionadas: primero, el ineficiente comportamiento del sector público; segundo, su excesiva depen- 
dencia de las materias primas, cuya volatibilidad en los precios ha llevado a una considerable disminución de los ingresos, y, tercero, las guerras civiles(6). Además, a su juicio, la dependencia de los productos primarios ha provocado distorsiones en los sistemas impositivos, por cuanto los gobiernos locales han confiado en demasía en los gravámenes directos e indirectos sobre estos productos.

Por su parte, los más críticos, como los teóricos de la dependencia, insisten en su planteamiento central: la pobreza que vive la mayoría de los Estados postcoloniales es precisamente el resultado de la modernización de las economías más desarrolladas, por cuanto éstas solo han podido mantener sus niveles de riqueza a partir de la explotación de las economías de países dependientes que producen materias primas a bajo costo. En otras palabras, el impulso de las economías más pobres no sucederá sin una ruptura radical de los vínculos económicos con los llamados países desarrollados.

De este modo, se está ante un complejo escenario en el que los países africanos deben navegar entre las complicaciones propias de sus realidades domésticas y las dinámicas sistémicas que impulsan - por una parte- su total externalidad, es decir, su dependencia en extremo del mundo occidental $y$, por otra, la tutela internacional, aquella ejercida por comunidades de donantes, tendiente a establecer los parámetros básicos de la organización política y económica de los Estados africanos(7).

Así, la política exterior de cada uno de ellos es el resultado de la conjugación de una serie de estrategias de inserción internacional, que propenden a superar los problemas derivados del desarrollo y los conflictos internos, destacando entre éstas su apego a las directrices fijadas por los poderes globales y las organizaciones intergubernamentales, en el marco de la cooperación para el desarrollo.

\section{La cooperación para el desarrollo y la ética glo- bal}

Los debates en torno a la ética de la cooperación para el desarrollo4 están necesariamente vincula-

\footnotetext{
${ }^{4}$ Toda actividad llevada a cabo por los agentes de cooperación (gubernamentales y no gubernamentales), con el fin proceder a la eliminación de la pobreza y la reducción de las desigualdades Norte-Sur, como elementos estructurales del subdesarrollo. Dichas actividades conllevan
}

dos con las opiniones sobre la exactitud de los argumentos económicos e históricos que sustentan la idea de desarrollo, como también con los planteamientos sobre la conveniencia de que todas las economías se basen en el modelo de los países industrializados. $\mathrm{Al}$ respecto, existen argumentos éticos que plantean que la ayuda es moralmente justificable, como también es posible encontrar planteamientos que, si bien consideran la cooperación como una exigencia ética, cuestionan las justificaciones de la misma y las concepciones reduccionistas del desarrollo.

Por ejemplo, para Amartya Sen(9) y Martha C. Nussbaum(10) el desarrollo no debe identificarse con la maximización de la riqueza, sino con los resultados alcanzables por medio de ésta, es decir, una vida próspera. A juicio de estos autores, una vida próspera implica no solo alcanzar cierto estándares de calidad de vida, sino fundamentalmente la capacidad de elegir entre diferentes prioridades. En otras palabras, dos personas que tienen logros idénticos no evidencian necesariamente una vida próspera si uno de ellos tiene la opción de elegir su destino y la otra no.

Al priorizar la prosperidad humana, ambos autores se inspiran en ética de la virtud, pero también vinculan la prosperidad a la idea de que hay ciertas condiciones universales para el florecimiento de cualquier ser humano, las cuales deben el objetivo de la cooperación para el desarrollo. Así, en consideración de esta visión, se establece un criterio para juzgar el nivel de desarrollo, lo cual hace más complejos y exigentes los objetivos para conseguirlo, ya que este criterio también llama la atención sobre la importancia de las prácticas e instituciones sociales y culturales necesarias para fortalecer las condiciones requeridas para el florecimiento humano. Algunas de estas condiciones son: capacidad de vivir en comunión con el entorno natural, buena salud, integridad corporal, educación, afectividad, recreación, participación en las decisiones políticas, respeto del derecho de propiedad, trabajo en igualdad de condiciones con los demás, entre otras(11).

inherentemente un componente de concesionalidad, pudiendo efectuarse bajo cualquiera de las formas de cooperación, en virtud de los intereses del país receptor y las dimensiones del desarrollo humano y sostenible(8). 
Estas condiciones constituyen requerimientos éticos mínimos para el alcance de una vida próspera, ya que estas capacidades humanas se basan tanto en tradiciones contractualistas como deontológicas y, por tanto, proporcionan la base unificadora necesaria para una ética del desarrollo. Sin embargo, las críticas a estos requerimientos éticos mínimos apuntan a que constituyen un ejemplo de la falsa universalización de supuestos morales parroquiales, como también una tendencia a atribuir las causas de subdesarrollo a la cultura y no al funcionamiento de la economía política global. En otras palabras, la ayuda al desarrollo presta muy poca atención a cómo la estructura económica neoliberal provoca y mantiene en el mundo desigualdad y pobreza, al mismo tiempo que hace más ricos a los ricos y más pobres a los pobres(12).

En este sentido, una de las cuestiones éticas planteadas por la cooperación para el desarrollo no solo se refiere a lo que ésta trata de lograr, sino también a cómo debe llevarse a cabo. De este modo, contrario a la impresión dada por el término, la "cooperación" para el desarrollo no es un simple regalo de parte de los países ricos a los pobres - por cuanto está ligada a una relación bilateral y multilateral de larga data, como también a menudo se manifiesta de diversos modos-, ya que es un instrumento de política exterior utilizado para consolidar relaciones mutuamente ventajosas entre los Estados o entre las elites de éstos. Así, por ejemplo, se conceden ayudas para la construcción de una represa en el país receptor, pero las obras de ingeniería que se requieren para ello son llevadas a cabo por el país donante.

Además, generalmente la ayuda bilateral entre los Estados refleja vínculos coloniales pasados, como también se encuentra ligada a una serie de condiciones políticas y/o económicas, destacando entre éstas los planes de ajuste estructural impuestos a los Estados beneficiarios durante la década de los ochenta. Del mismo modo, tanto los mecanismos de gestión y rendición de cuentas de los presupuestos, como la ejecución de los proyectos de cooperación están a menudo en manos de extranjeros y no de personeros locales.

Desde un punto de vista utilitario, la entrega de ayuda en los términos recién expuestos es un pro- blema moral en la medida en que falla en maximizar el resultado del desarrollo. En efecto, existen evidencias que sugieren que las políticas de cooperación para el desarrollo no han cumplido con este fin; por el contrario, a menudo vienen a enriquecer las elites locales y no toman en cuenta la realidad de la región ni en la definición ni en la ejecución de los proyectos. Así, la cooperación para el desarrollo bajo un esquema de condicionalidades es una política esencialmente paternalista que pone entredicho la autonomía y las capacidades humanas.

Del mismo modo, diferentes enfoques sobre la práctica de cooperación se han fundado en consideraciones teóricas del desarrollo humano, poniendo énfasis en la participación y empoderamiento de los beneficiarios. En efecto, la entrega de ayuda se ha delegado en organizaciones de la sociedad civil internacional que requieren del activo involucramiento de grupos locales, con el fin de incorporar sus objetivos e impulsar así efectivos planes de reducción de la pobreza. A juicio de Fiona Robinson, este tipo de cambios son manifestaciones de un alejamiento de la universalidad abstracta de posiciones éticas tradicionales en materia de ayudas, por cuanto la participación popular en la construcción y ejecución de estos proyectos cumple con dos metas: por una parte, reconoce el valor ético de la cooperación entre las personas y, por otro, crea un contexto en el cual las necesidades se abordan de manera comprehensiva y no separadas en varias categorías(13).

Estos enfoques no solo reconocen un problema moralmente cuestionable, como la pobreza, sino también se guían por una ética que, primero, rechaza cualquier separación entre economía, política y moral, y, segundo, reconoce el potencial transformador de recursos intangibles como la solidaridad(11). De este modo, el valor ético de la ayuda es inherente tanto al proceso de entrega de ésta como a los resultados.

Por otra parte, quienes se oponen a la cooperación para el desarrollo plantean en general que ésta es ineficaz e incluso contraproducente, ya que exacerba en el tiempo los problemas de escasez de recursos. Del mismo modo, la crítica marxista a este tipo de ayuda encuentra sus raíces en la ética de la virtud, por cuanto sostiene que el capitalis- 
mo no es conductor de la prosperidad humana y, en consecuencia, la cooperación para el desarrollo solo viene a sostener y promover, en un nivel global, un modelo esencialmente injusto(14).

Del mismo modo, si bien otros autores incluso afirman que tal ayuda puede ser buena para los receptores, no existe una obligación ética de los países ricos de asistir a los más pobres. En efecto, a juicio de Robert Nozick debe priorizarse la libertad individual, por lo cual una redistribución de la riqueza, tanto en el marco del Estado como a través de programas de ayuda más allá de éste, es una violación de los derechos de propiedad de las personas y, en consecuencia, moralmente cuestionable(15).

Asimismo, a partir de la ética de la virtud, el florecimiento humano siempre responde a un contexto, nutriéndose activamente a través de una permanente interacción con los que comparten una forma de vida. De este modo, si bien no se excluye necesariamente la ayuda a los extranjeros, sí se rechaza la imposición a una sociedad de valores inherentes a una forma de vida distinta, por lo cual se refuta el discurso universalista del desarrollo, sobre todo aquellas versiones que se basan en un paradigma de modernización(16).

\section{Globalización económica y cooperación para el desarrollo en África}

Luego de su independencia, particularmente entre 1960 y 1973, África mostró un crecimiento económico fuerte y sostenido. En efecto, durante el transcurso de estos ańos, 11 de los 29 países de los cuales existen datos disponibles mostraron un crecimiento anual en las exportaciones entre un 10 y un 26\%; del mismo modo que 17 de ellos invirtieron en promedio entre el 5 y el $31 \%$ de su $\operatorname{PIB}(17)$.

Sin embargo, en los años venideros se produjo en el continente africano una intempestiva caída del PIB, arguyéndose como causas de este fenómeno el mal gobierno, la inestabilidad política, las características geográficas y los acontecimientos históricos recientes (por ejemplo, el colonialismo). Esta negativa tendencia llevó en África a una disminución del capital humano y físico, a la dependencia de la exportación de materias primas, a una baja productividad y a una alta volatilidad del crecimiento económico. De acuerdo con datos estadísticos del Banco Mundial, los países africanos han experimentado más volatilidad en el crecimiento que otras regiones, alcanzando éstos en su conjunto, entre 1960 y 2000, una media de crecimiento del ingreso per cápita del $0,9 \%$, esto es, un 1,5\% menos que otros países en vías de desarrollo y aproximadamente un 3\% menos que el mostrado por las economías africanas de mejor rendimiento (Botswana e Islas Mauricio)(18).

Igualmente, los indicadores sociales de África evidenciaron permanentemente serios problemas que contrastaban con el auspicioso crecimiento económico de los primeros ańos de vida independiente. Por entonces, a modo de ejemplo, la esperanza de vida al nacer oscilaba entre 32 años en Sierra Leona y 61 años en las Islas Mauricio; la tasa de mortalidad era de 91 muertes por cada 100 nacidos vivos en Rhodesia (hoy Zimbabwe); el acceso al agua potable alcanzaba una tasa que iba entre el 10 y $30 \%$ de la población adulta, y más del 80\% de ésta era analfabeta(17).

A partir de los años noventa, los países de África se verán arrastrados por el peso del sistema capitalista, lo cual ha impactado fuertemente en la reducción del Estado y sus instituciones, en una deslegitimidad de la actividad política, en un ahondamiento en las desigualdades sociales, en el agudizamiento de los conflictos internos y en la injerencia de entidades financieras internacionales en las decisiones soberanas de cada país.

En la actualidad, por ejemplo, las perspectivas económicas de África están sujetas a varios riesgos e incertidumbres, por cuanto la extroversión de los países africanos condiciona su desempeño al crecimiento de sus principales socios comerciales y donantes; lo cual no deja de ser preocupante, aun cuando algunos de los indicadores macroeconómicos del continente son algo más alentadores, destacando el año 2010 el control de la inflación y el leve deterioro del déficit fiscal (5,8\% del PIB) (19).

Por otra parte, en el actual escenario, los gobiernos locales son incapaces, primero, de diseñar e implementar de manera independiente sus propias agendas de desarrollo nacional; segundo, de 
controlar las distintas operaciones políticas y económicas que están teniendo lugar en sus respectivos territorios, y, tercero, de impedir la subordinación de África en el ámbito internacional(20). En efecto, se desacreditó la intervención del Estado en la economía; no obstante, los hechos han evidenciado que sin él, por ejemplo, los pequeños agricultores han visto disminuir su acceso al capital, se han convertido en deudores y han sido desempoderados hasta tal punto de no poder influir en los precios, en los procesos de calidad y en la diferenciación de los productos(21).

Asimismo, la Organización Mundial del Comercio argumenta que el fin de las barreras arancelarias propicia una mayor producción y, por ende, mayores beneficios a los cultivadores y comerciantes africanos; sin embargo, la realidad es muy distinta: las compañías transnacionales bloquean los mecanismos de oferta y demanda con el fin de obtener un abastecimiento de materias primas a bajo costo, controlar las cadenas de producción de mercancías y conseguir la mayor parte de los beneficios. Entonces, de no cambiar drásticamente esta tendencia los años venideros, las materias primas provenientes de los países africanos continuaran desvalorizándose sin pausa, requiriéndose, por tanto, definiciones políticas que devuelvan cierto poder a los productores en cuanto a su capital financiero, humano y tecnológico.

Por otra parte, no es posible concluir que los procesos de liberalización de las economías locales estén incidiendo significativamente en la disminución de la pobreza, dado que la mayoría de la población pobre no puede acceder a la cadena de valor global. En efecto, en muchos países africanos los indicadores macroeconómicos básicos han llevado a análisis parciales que solo ocultan el impacto real de las dinámicas de la globalización; las cuales, en definitiva, han contribuido a la destrucción de un entramado productivo interno incapaz de competir con productos importados(22), han ahondado el desempleo en el sector menos cualificado de la población activa y han aumentado las relaciones exteriores de carácter dependiente(23).

Además, los gobiernos africanos deben comprender que el sector informal de la economía no es el origen de las futuras empresas africanas y el primer paso para una inserción en la economía glo- bal, sino principalmente un mecanismo de subsistencia básica. Como señala Antonio Santamaría, si bien los africanos han desarrollado sus propias formas de ahorro e inversión apelando a sus escasos recursos, es irreal pensar que solo a través de una inyección de capital podrá impulsarse el despegue a gran escala de una actividad comercial o productiva, por cuanto, primero, muchos son analfabetos, carecen de estudios y su única escuela es la experiencia cotidiana; segundo, porque no tienen medios para desarrollar o acceder a tecnologías adecuadas que permitan conservar y revalorizar los productos con que comercian, y, tercero, porque la demanda de bienes y servicios entre los pobres es muy escasa y barata, ya que los compradores y clientes no tienen dinero(24).

Por otra parte, los partidarios del neoliberalismo sostienen que los planes de ajuste estructural en África eran necesarios e inevitables; sin embargo, se obvió que medidas como éstas desatan o exacerban conflictos internos, quitan absoluta independencia a los bancos centrales locales, obligan a destinar un porcentaje mayoritario de los ingresos fiscales al pago de la deuda externa y no a la inversión pública, implican un proceso de desindustrialización y debilitan la capacidad productiva de los países africanos. Es más, de acuerdo con los diversos informes anuales sobre desarrollo humano publicados por el Programa de Naciones Unidas para el Desarrollo (PNUD), gracias a estas políticas la gran mayoría de los países africanos se encuentra cada vez más engullida por la pobreza extrema, el desempleo masivo, las tasas crecientes de analfabetismo, la falta de acceso a salud, agua potable y saneamiento, la malnutrición, la morbilidad y la mortalidad materno-infantil(25).

En este escenario, es deber de los Estados africanos corregir las inequidades del mercado, respondiendo así a las expectativas de una ciudadanía afligida que requiere de prestaciones sociales básicas para superar su permanente situación de vulnerabilidad. Para la Comisión Económica de las Naciones Unidas para África, un buen sistema de protección social — como también cualquier política encaminada al cumplimiento de los Objetivos de Desarrollo del Milenio (ODM) — ayuda a los hogares a nivelar el consumo, desarrollar el capital humano, acumular bienes de producción y participar en el mercado laboral, porque el riesgo, 
la vulnerabilidad y la privación son fundamentales en la generación de la pobreza transitoria o crónica(26).

En una visión que resalta los logros alcanzados, Manuel de la Rocha y Laura Gómez sostienen que es posible evaluar de manera positiva los esfuerzos hechos en África, tanto localmente como por parte del sistema de Naciones Unidas, para contrarrestar los efectos negativos de la agenda neoliberal en el plano social(27). Para ellos, si bien el cumplimiento de los ODM el año 2015 es aún lejano, no es menos cierto que 10 países africanos —entre ellos Etiopía y Angola - han reducido a la mitad su tasa de pobreza; la tasa de escolarización aumentó del 52 al 74\% entre 1991 y 2007; se evidencian avances en términos de paridad de género; ha disminuido la mortalidad de niños menores de cinco años y los servicios de salud materna han ampliado su cobertura.

En paralelo a la discusión en torno al cumplimiento de los ODM en los países africanos, surge un debate sobre los reales beneficios de la cooperación para el desarrollo, por cuanto los últimos veinte años estas políticas se han caracterizado por sus escasos resultados, en virtud de la aplicación de los planes de ajuste estructural, la crisis de la deuda, la fatiga de los donantes, la condicionalidad política y el "buen gobierno" (28). Pablo Gutiérrez Vega plantea que este "catálogo" de valores jamás ha gobernado la política africana, por lo que resulta difícil implantarlos en el corto plazo en un tejido social si no diametralmente ajeno a las instituciones de tal naturaleza, al menos poco receptivo a vuelcos expeditivos de la esencia de la cultura política local(29).

Del mismo modo, Rosa Alcalde y Jokin Alberdi sostienen que la condicionalidad política hace aun más notoria la confrontación Norte-Sur por el control del Estado postcolonial africano y la definición de nuevas fronteras de soberanía, con un claro saldo a favor de los donantes(30). En efecto, amparados en la versatilidad del término, los donantes lograron reducir la reticencia de los gobiernos locales a la inclusión de dimensiones más políticas en los programas de cooperación, facilitándose así la influencia directa del Banco Mundial y el PNUD en aspectos centrales del funcionamiento estatal: sistemas de gestión pú- blica, transparencia y rendición de cuentas, definición de políticas, promoción de la seguridad jurídica y el Estado de Derecho, y la regulación de las relaciones entre el Estado y sus sociedades.

Además, la cooperación para el desarrollo ha sido cuestionada en virtud de sus implicancias macroeconómicas. De acuerdo con Carlos Oya y Nicolás Pons-Vignon, uno de los mayores problemas que los economistas asocian a la afluencia de donaciones externas y créditos son los perniciosos efectos en los índices de competitividad internacional, por cuanto estas intervenciones distorsionan los tipos de cambio y los mantienen por encima de los niveles que prevalecerían en ausencia de ayuda externa ("sindrome holandés") (31). Para los autores, se encuentra en entredicho en el plano institucional uno de los mayores objetivos de la cooperación internacional: el desarrollo de capacidades ("capacity building"), ya que —en consideración de las reformas estructurales aplicadas en los países africanos- existe una creciente dependencia de estos recursos para la gestión gubernamental de carácter operacional; las exigencias del Fondo Monetario Internacional han exigido una contracción del gasto público en educación y salud, y se evidencia un aprovechamiento, por parte de las burocracias estatales, de la gestión de los proyectos de cooperación en pro de obtener una compensación adicional (por ejemplo, sueldos y dietas).

En suma, el fracaso o carencia de legitimidad de este tipo de políticas responde a su instrumentalización por parte de los grandes poderes globales en pro de la consecución de sus propios intereses políticos, estratégicos y comerciales, obviándose completamente a la población africana y sus autoridades durante el proceso de diseño, implementación y evaluación. Del mismo modo, parece lejana a la realidad africana la concreción de un modelo de asociación basado en los principios de apropiación, alineamiento, armonización, corresponsabilidad y gestión por resultados, por cuanto el mantenimiento de las redes clientelares impide un compromiso de los gobiernos locales con el bienestar de toda la población.

\section{Conclusión}

El concepto de desarrollo imperante ha supuesto 
que el crecimiento económico y la apertura comercial pueden resolver los problemas de escasez en África, como también ha llevado a sostener, de manera categórica, que lo único necesario para salir de la pobreza es que los Estados e individuos más ricos tiendan una mano a los pobres.

Sin embargo, esta concepción de desarrollo ha contribuido, por una parte, a profundizar ciertas formas de escasez y, por otra, a difundir un estándar de civilización que ha tenido y sigue teniendo un efecto dañino en la población más pobre de África. Por lo tanto, el debate sobre la ética de la cooperación para el desarrollo es inseparable de dos preguntas cruciales: primero, ¿cómo funciona la economía mundial en su conjunto? Segundo, ¿qué papel y responsabilidad caben a los diferentes actores dentro de ella?

En otro ámbito, el debate sobre la cooperación para el desarrollo ha girado en torno a dos cuestio- nes: la ayuda es una obligación de la humanidad o un acto discrecional en la escena internacional. Si la ayuda es una obligación de la humanidad, lo importante es el resultado de la cooperación, por lo cual, es aceptable éticamente una intervención en el Estado receptor con el fin de asegurar un alivio a los más necesitados. Por el contrario, si la ayuda es un acto discrecional, entonces el donante no tiene derecho a interferir en los asuntos internos del país receptor.

De este modo, el paternalismo que evidencia la cooperación para el desarrollo en África sugiere que se necesita una comprensión mucho más completa de los requisitos éticos implícitos en las relaciones entre los países ricos y pobres. En este sentido, el punto de partida es pensar en la ética del desarrollo con el fin de reflexionar sobre las cuestiones de justicia distributiva mundial.

Referencias

1. Peñas F. Hermanos y enemigos. Liberalismo y relaciones internacionales. Madrid: Los Libros de la Catarata; 2003.

2. Duffield M. Las nuevas guerras en el mundo global. La convergencia entre desarrollo y seguridad. Madrid: Los Libros de la Catarata; 2001.

3. Ruiz-Giménez I. Las “buenas intenciones”. Intervención humanitaria en África. Barcelona: Icaria; 2003.

4. Campos A. Introducción. Discursos y prácticas del desarrollo en África: ¿¿iálogos convergentes? En: Campos A, (ed.) Ayuda, mercado y buen gobierno. Los lenguajes del desarrollo en África en el cambio de milenio. Barcelona: Icaria; 2005: 11-36.

5. Rist G. El desarrollo: historia de una creencia occidental. Madrid: Los Libros de la Catarata; 2002.

6. Collier P. La trampa africana del desarrollo. Claves de Economía Mundial 2005; 5: 616-623.

7. Peñas F. Diplomacia humanitaria, protectorados y política de cañoneras. En: Peñas F, (ed.) África en el sistema internacional. Madrid: Libros de la Catarata; 2000: 51-83.

8. López G, Molina de la Torre I. Introducción a la solidaridad internacional. La cooperación para el desarrollo. Valladolid: Universidad de Valladolid; 2000.

9. Sen A. The Concept of Development. In: Chenery H, Srinivasan T, (eds.) Handbook of Development Economics, Vol. 1. North Holland: Elsevier Science Publishers; 1988: 10-26.

10. Nussbaum M. Women and Human Development. The Capabilities Approach. Cambridge: Cambridge University Press; 2000.

11. Hutchings K. Global Ethics. An Introduction. Malden (MA): Polity Press; 2010.

12. Jaggar A. "Saving Amina": Global Justice for Women and Intercultural Dialogue. Ethics \& International Affairs 2005: 19(3): 85-105.

13. Robinson F. Globalizing Care: Ethics, Feminist Theory, and International Relations. Boulder (CO): Westview; 1999.

14. Nielsen K. Is Global Justice Impossible? Res Publica 1998; IV(2): 131-166.

15. Nozick R. Anarchy, State and Utopia. Oxford: Blackwell; 1974.

16. Gasper D. The Ethics of Development. Edinburgh: Edinburgh University Press; 2004.

17. Lawrence P. The African Tragedy. International and National Roots. In: Padayachee V, (ed.) The Political Economy of Africa, New York: Routledge; 2010: 19-38.

18. Jones V. U.S. Trade an investment Relationship with Sub-Saharan Africa: The African Growth and Opportunity Act. In: 
Fiala N, (ed.) Sub-Saharan Africa. Economic Issues, New York: Nova Science Publishers, Inc.; 2011: 1-39.

19. United Nations Economic Commission for Africa. Economic Report on Africa 2011. Governing development in Africa: The role of the state in economic transformation. Addis Ababa: United Nations Economic Commission for Africa; 2011.

20. Kabunda M. África en la globalización neoliberal: las alternativas africanas. Revista Theomai 2008; 17: 77-87.

21. Daviron B, Gibbon P. Global commodity chains and African export agriculture. Journal of Agrarian Change 2002; 2(2): 137-161

22. Lawrence P. El comportamiento del sector manufacturero en el África Subsahariana. En: Oya C, Santamaría A, (eds.) Economia politica del desarrollo en África, Madrid: Akal; 2007: 187-209.

23. Santamaría A. Comercio, globalización e integración regional. En: Oya C, Santamaría A, (eds.) Economía politica del desarrollo en África. Madrid: Akal; 2007: 211-238.

24. Santamaría A. Desarrollo y subdesarrollo en África. En: Echart E, Santamaría A, (coords.) África en el horizonte. Introducción a la realidad socioeconómica del África Subsahariana. Madrid: Los Libros de la Catarata; 2006: 140-164.

25. United Nations Development Programme. Human Development Report 2011. Sustainability and Equity: A Better Future for All. New York: Palgrave Macmillan; 2011.

26. United Nations Economic Commission for Africa. MDG Report 2011: Assessing Progress in Africa toward the Millennium Development Goals. Addis Ababa: United Nations Economic Commission for Africa; 2011.

27. De la Rocha M, Gómez L. África: una visión optimista. Economía Exterior 2010; 55: 41-49.

28. Alberdi J, Alcalde R. Cooperación para el Desarrollo en África Subsahariana: entre la ambivalencia del discurso y la complejidad de las realidades africanas. En: Echart E, Santamaría A, (coords.) África en el horizonte. Introducción a la realidad socioeconómica del África Subsahariana. Madrid: Los Libros de la Catarata; 2006: 220-252.

29. Gutiérrez P. Tipicidad y casuística de la condicionalidad política: la Unión Europea y África Subsahariana. En: Peñas F, (ed.) África en el Sistema Internacional. Madrid: Libros de la Catarata; 2000: 267-296.

30. Alcalde R, Alberdi J. Gobernabilidad y cooperación internacional al sur del Sahara. En: Campos A, (ed.) Ayuda, mercado y buen gobierno. Los lenguajes del desarrollo en África en el cambio de milenio. Barcelona: Icaria; 2005: 39-69.

31. Oya C, Pons-Vignon N. Aid, Development and the State in Africa. In: Padayachee V, (ed.) The Political Economy of Africa. New York: Routledge; 2010: 172-198.

Recibido: 26 de septiembre de 2013

Aceptado: 14 de octubre de 2013 